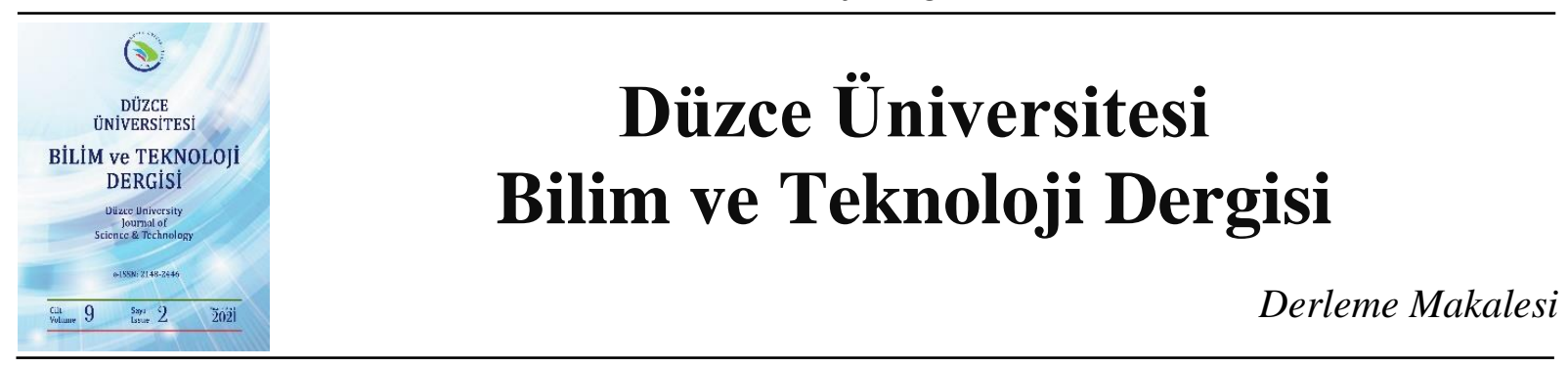

\title{
Mimarlıkta Bilgisayar Destekli Fabrikasyon Teknolojileri ve Kullanım Yaklaşımları
}

\author{
(D) Meltem EZEL ÇIRPI ${ }^{\mathrm{a}, *}$, (D) Dilan ÖNER ${ }^{\mathrm{b}}$ \\ ${ }^{a}$ Mimarlık Bölümü, Mimarlı ve Tasarım Fakültesi, Marmara Üniversitesi, İstanbul, TÜRKIYE \\ ${ }^{b}$ Mimarlı Bölümü, Mimarlı ve Tasarım Fakültesi, Kocaeli Üniversitesi, Kocaeli, TÜRKIYE \\ * Sorumlu yazarin e-posta adresi: m_ezel11@hotmail.com
}

DOI: 10.29130/dubited.799283

\begin{abstract}
ÖZET
Fabrikada üretimin ilk örnekleri 1912 yılında gemi endüstrisinde daha sonra diğer endüstrilerde görülse de fabrikasyonun dijitalleşmesi 1944 yılında ilk programlanabilir dijital bilgisayarın tasarlanması ile gelişmeye başlamış̧ır. Mimaride ise dijital tasarım ve üretim kavramları ile 1990'lardan başlayarak ivme kazanmıştır. Birçok bilim dalında kullanılan Bilgisayar Destekli Fabrikasyon Teknolojilerinin mimaride kullanımlarını ortaya koymak bu çalışmanın amacını oluşturmuştur. Bu kapsamda ilk olarak fabrikasyonun tanımı yapılarak kısaca tarihinden bahsedilmiştir. Ardından Mimaride sayısal fabrikasyonun gelişmesi, avantajları ve sayısal fabrikasyon teknolojilerinden bahsedilerek örnekler verilerek ele alınmıştır. Sonuç kısmında da bilgisayar destekli fabrikasyon teknolojileri mimari de kullanımlarına göre sınıflandırılmış ve mimaride kullanılmasının yarattığı değişimler tartı̧ılmış̧ır.
\end{abstract}

Anahtar Kelimeler: Mimaride fabrikasyon, Saylsal fabrikasyon teknolojileri, Saylsal fabrikasyon teknolojileri sinıflandırması, Sayısal üretim araçları ve metotları

\section{Computer Aided Fabrication Technologies in Architecture and Usage Approaches}

\begin{abstract}
Although the first examples of production in the factory were seen in the ship industry in 1912 and later in other industries, the digitalization of fabrication began to develop in 1944 with the design of the first programmable digital computer. In architecture, it has gained momentum starting from the 1990s with the concepts of digital design and production. The aim of this study is to reveal the usage of Computer Aided Fabrication Technologies in architecture. In this context, firstly, the definition of fabrication was made and its history was briefly mentioned. Then, the development of digital fabrication in Architecture, its advantages and digital fabrication technologies are discussed and examples are given. In the conclusion part, computer aided fabrication technologies are classified according to their use in architecture and the changes caused by their use in architecture are discussed.
\end{abstract}

Keywords: Fabrication in architecture, Digital fabrication technologies, Digital fabrication technologies classification, Digital production tools and methods

Geliş: 23/10/2020, Düzeltme: 01/02/2021, Kabul: 04/02/2021 


\section{GIRIS}

Endüstri ve teknoloji alanında gerçekleşen devrimler her alanda olduğu gibi mimarlık alanında da birçok değişim ve dönüşümü beraberinde getirmiş̧ir. İlkel insanların ortaya koyduğu mağaralardan başlayan ve gökdelenlere kadar olan süreçte ki değişim ve dönüşüm ile birlikte mimarlık alanında düşünme, tasarlama, üretim biçimleri de değişmiş̧tir. Bu kapsamda en büyük değişimlerden birisi de el yapımından makine yapımına ve sayısal yapıma doğru giden üretim biçimlerinde gerçekleşmiştir. Bunun mimarlıktaki yansıması da sayısal fabrikasyon olarak karşımıza çıkmaktadır. İlk başlarda mimari de sayısal fabrikasyon, maket yapımında kullanılsa da ilerleyen dönemlerde yap1 elemanı ilişkilerinin tasarlanmasında kullanılmıştır. Günümüzde gelinen en son noktada ise sayısal fabrikasyon yöntemleri ile yapıların tamamının üretimi üzerine gerçekleştirilen çalışmalara yoğunlaşılmıştır. Bu süreçte mimarlar, sayısal üretim ile tasarım süreci dışındaki üretim süreçlerine doğrudan dâhil olup, tüm sürece müdahale edebilir duruma gelmiştir. Bu açıdan mimarların sayısal üretim, araç ve yöntemleri konusunda bilgisinin olması kaçınılmaz bir hale gelmiştir. Bu makalede de bu amaçla mimarlara yol gösterici olmak adına bilgisayar destekli sayısal fabrikasyon teknolojileri ve kullanım yaklaşımları ortaya koyularak bir sınıflandırma yapılmıştır.

\section{FABRİKASYON TANIMI VE TARIHHCESI}

Mario Carpo [1], el yapımı (hand making), makine yapımı (machine making) ve sayısal yapım (digital making) olmak üzere üç farklı yapım şekli olduğundan bahsetmektedir. Fabrikada yapılarak (üretilerek) tüketime hazır duruma getirilen madde olarak tanımlanan fabrikasyon terimi, Carpo'nun bahsettiği makine ve sayısal yapım şekillerini kapsamaktadır. Fabrikada üretimin ilk örnekleri 1912 yılında gemi, 1917 yılında havacılık ve 1937 yılında ise tekstil endüstrisinde karşımıza çıkmaktadır [2, 3]. 1944 y1lında ilk programlanabilir dijital elektronik bilgisayar olan Colossus'un, Tommy Flowers tarafindan tasarlanması fabrikasyonun dijitalleşme sürecinin bilgisayar teknolojisine paralel olarak gelişmeye başladığını göstermektedir. Yine bu gelişime paralel olarak 1952 yılında ilk delikli kart ile programlanabilir freze makinası, kompleks uçak parçalarının üretimi için havacılık sektöründe kullanılmaya başlanmıştır. 1959 yılından itibaren bilgisayar teknolojisindeki ROM'ların (read only memory) kullanılmaya başlanması ile CNC'ler, genel amaçlı işlemciler ve özel geliştirilmiş APT'ler (automatically programmed tools /otomatik programlanmış araçlar) ile programlanmak suretiyle üretim de sayısal üretimin yine öncü aşamaları olarak tarihe geçmiştir [4, 5]. 1954'te George Charles Devol, ilk endüstriyel robot olan Unimate'i icat etmiştir. 1969 yllında ise Victor Scheinman, bilgisayar kontrollü montaj ve otomasyon yapabilen ilk altı eksenli mekanik manipülatör olan Stanford Arm'ın mucidi olmuştur. 1985 yılında ise Carl Deckard ve Joe Beaman çizimden çıktı alabilen 3boyutlu yazıcıyı bilim dünyasına kazandırmıştır [6-8].

\section{MIMARIDE SAYISAL FABRIKKASYON}

Diğer disiplinlerde fabrikasyon teknolojilerindeki gelişmeler devam ederken, mimaride kullanımı ise 1990'larda görülmeye başlamıştır. Streich ve Weisgerber [9] tarafından 1996 yılında yayınlanan "Bilgisayar Destekli Mimari Model Oluşturma" adlı kitap mimari tasarım sürecinde sayısal üretim konusunun bütüncül bir çalışma olarak ele alındığı ilk çalışma olarak karşımıza çıkmaktadır. 1997 yılında Alvise Simondetti [10] ise "Mimari Tasarımın Erken Aşamalarında Hızlı Prototipleme" başlıklı çalışması ile dijital üretimin mimari modeller yapmak için nasıl kullanılabileceğini ele almıştır. 2003 y1lında Delft Teknoloji Üniversitesi'nde Breen vd. [11], CNC freze makinelerinin, lazer kesicilerin ve üç boyutlu yazıcıların mimari model oluşturma sürecinde nasıl kullanılabileceği üzerine bir çalışma gerçekleştirmiş̧ir [12].

Fabrikasyon teknolojilerindeki gelişmelere paralel olarak 2000'li yıllarda sayısal fabrikasyon araçlarının ucuzlaması ve internet üzerinden açık kaynak kodlara ulaşımın sağlanması, sayısal fabrikasyon yöntem 
ve araçlarının mimaride yaygınlaşmasına önemli bir etken olmuştur [13]. Bunun yanı sıra hızlı prototipleme yöntemi ve 3 boyutlu yazıcı gibi sayısal fabrikasyon araçları ile sayısal üretim sürecinin, kişiye ve üretime yönelik olarak özelleşmesi de, mimari tasarımın yapılabilir ve özgün olmasını sağlayan diğer bir etken olmuştur. Dijital fabrikasyon araçlarının ofisler ve üniversiteler tarafından kullanılması yaygın hale geldikçe, tasarımcıların ve araştırmacıların dijital fabrikasyon konularında yaptıkları çalışmalar ile yeni yöntemler keşfedilmeye başlanmıştır ve böylece mimarlarda tasarımlarına bu fabrikasyon süreçlerini dâhil eder olmuşlardır.

Botha ve Sass [14], malzeme ve tasarım kuralları ile sayısal fabrikasyonun ilişkisini, sayısal ortamda tanımlanan bir mimari tasarımın tamamının $\mathrm{CNC}$ ile üretilebilir olduğunu bir konut üzerinde göstermiştir. Gramazio ve diğ. $[15,16]$, sayısal fabrikasyon ile bilgisayarların bir arada kullanımı, tasarlama ve üretimi bir araya getirip iş akışını değiştirmekle kalmayıp, aynı zamanda mimarlı̆̆ın tasarım bilgisinin kapsamınının da genişlediğini belirtmektedir. Ayrıca sayısal fabrikasyonun, robotik üretim teknolojisi ile birlikte kullanımı ve diğer gelişmelerin, mimarlıkta yeni ifade ve ilişki biçimlerinin ortaya çıkmasında etkili olduğunu belirtmektedir. Rocha [17], mimaride sayısal fabrikasyon teknikleri ile karmaşık geometriler üretileceğini, bir başka deyişle öklid geometrisinden öklid dışı geometri kavramı olan yüzey ötesi kavramına geçilerek tasarımlarda ulaşılamayan formlara ulaşmanın mümkün olduğunu ifade etmektedir. Scheurer [18], birebir ölçekte üretimde, standart olmayan yapı elemanı geometrisinin üretiminden önce yapılacak optimizasyonlar (en iyileme) ile maliyetin düşürülebileceğinden, yapının birbirine komşu elemanlarının geometrisinin sadeleştirilmesi gerektiğinden, birleştirme detaylarının bir kez çözüldükten sonra CNC için standart olmayan biçim ve geometri üretiminin sadece sayısal bilginin değiştirilmesinden ibaret olduğunu bildirmektedir. Örnek olarak, Kas Ossterhouse ONL grup ile tasarladığg 1,5 km'lik akustik bariyerin standart yöntemlere göre yarı yarıya maliyet ile yapıldığını belirtilmektedir.

Özet ile mimaride sayısal fabrikasyonun amaçları aşağıdaki gibi sıralanmaktadır;

- Mekânı ve malzemeyi yeniden farklı olasılıklar üzerinden düşündürmeyi sağlamaktadır.

- Yeni ve farklı detay çözümleri elde edilmektedir.

- Statik ve dinamik açıdan malzemenin sınırları zorlanmaktadır.

- Malzeme performans eşikleri arasında sentezlenmiş bir formülasyon ortaya çıkarılmasını sağlamaktadır.

- Geleneksel üretimde biçime bağlı kullanımı zor veya uygun olmayan malzemelerin yapım sürecine dâhil edilmesini sağlamaktadır.

- Algoritmalar ile denetlenen fiziksel çevre olaylarının tasarıma yansıtılmasını sağlamaktadır.

- Çevresel zararların sonuçlarını azaltarak daha iyi bir çevre yaratmayı sağlamaktadır.

- Tasarımın tasarlandığı şekliyle (file to factory) dosyadan fabrikasyona göndermeyi sağlamaktadır.

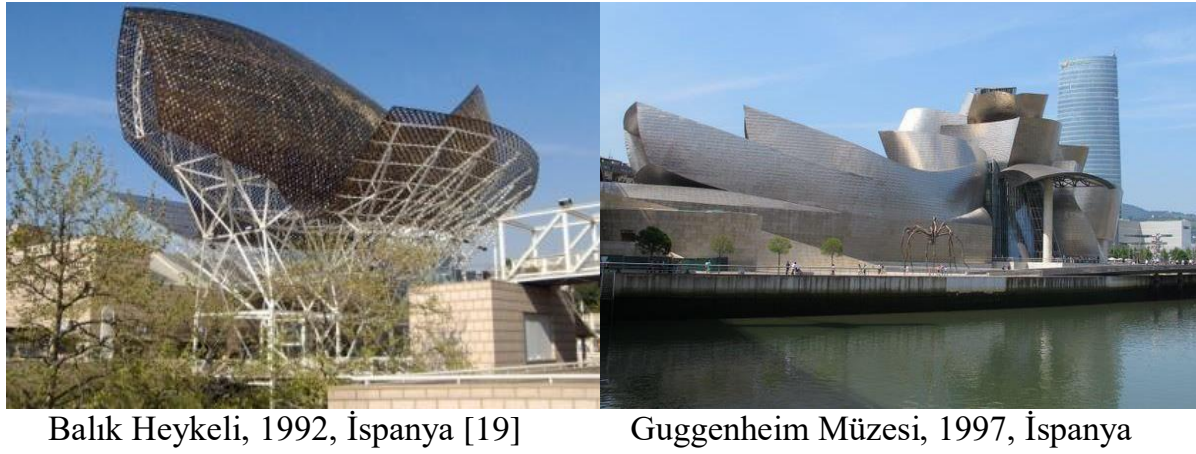

[20]

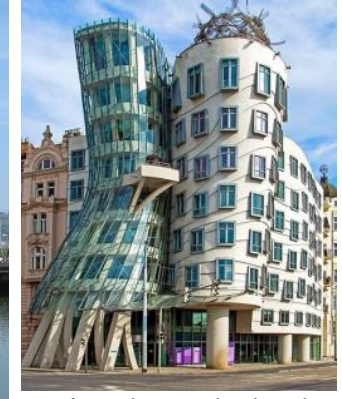

Nationale-Nederlanden Binas1, 1996, Prag [21]

Şekil 1. Sayısal üretim ile yapılan projeler.

\section{A. SAYISAL ÜRETIM ARAÇLARI, SINIFLANDIRMALARI VE TEKNIKLERİ}

Alberti'nin dediği gibi mimarlar artık sadece tasarımdan sorumlu değil, Antoine Picon'un dediği gibi mimar binanın tasarladığı gibi üretilmesinden de sorumlu hale gelmiştir [19]. Dolayısıyla mimarlar, sayısal üretim ile tasarım süreci dışındaki üretim süreçlerine doğrudan dâhil olup, tüm sürece müdahale 
edebilir duruma gelmiştir. Kolarevic [20] ise günümüzde bilgisayarda hesaplanabilen her şeyin üretilebilmesinin mümkün olduğunu, sorulan sorunun "bu form yapılabilir mi?" değil, "bu formu üretecek sayısal araçların olup olmadığı" ifadeleri ile bildirmektedir. Bu bağlamda mimari de sayısal üretim ile ilgili çeşitli yöntemler ortaya atılmaktadır. $\mathrm{Bu}$ yöntemler yapılan tasarımın, tasarım aşamalarını ve nasıl üretileceği hakkında çeşitli yaklaşımlar sunmaktadır. Projenin verilerine, sınırlarına göre tasarım yöntemine karar verilerek tasarlama süreci başlamaktadır. Bu süreçte yapı elemanları ve bileşenlerinin detaylandırması ve dijital üretim yöntemleri ile nasıl üretileceği de düşünülmesi gerekmektedir. Bu kapsamda sayısal olarak tasarlanan ürünlerin üretilmesi için çeşitli sınıflandırmalar, bu sınıflandırmalara göre nasıl üretilip biçim verileceği ile ilgili teknikler, bu sınıflandırma ve teknikleri aktive edebilmek için de algoritmalar ortaya koyulmaktadır. Bu yüzden sayısal olarak tasarlanan modellerin üretilmesi için sayısal üretim araçları, sayısal üretim biçimleri ve sayısal üretim metotları arasındaki ağın iyi çözümlenmesi gerekmektedir.

\section{A. 1. Sayısal Üretim Araçları}

Sayısal üretim araçlarının seçiminde, ürünün nasıl tasarlanacağı, nasıl uygulanacağı ve hangi araçlar kullanılarak üretileceği etkili olmaktadır. Seely [12], sayısal üretim araçlarını CNC (computer numerical control - bilgisayarlı sayısal kontrol) ve hizlı prototipleme olarak sınıflandırmaktadır. Dunn [21] ise, sayısal üretim araçlarını kesim (lazer ve $\mathrm{CNC}$ ), $\mathrm{CNC}$ freze ve kanal açma, hızlı prototipleme, 3B tarama ve robotlar olmak üzere 5'e ayırmıştır. Bu sınıflandırmadan yola çıkarak sayısal üretim araçları Cnc, hizlı prototipleme, robotlar olarak sinıflandirabiliriz (Tablo 1).

\section{A.1.1. CNC (Computer Numering Control - Bilgisayarlı Saytsal Kontrol)}

Günümüzde CNC'ler oldukça gelişmiş olup, çeşitli bilgisayar ara yüzleri ile kontrol edilebilmekte ve 25 eksenli çalışabilmektedir. CNC'ler de yaygın olarak frezeleme-oyma ve kesme ile malzemeye form verilebilmektedir. Karmaşık üretim prosedürleri ve bunların simülasyonları çeşitli ara yüzlerle gerçekleşebilmektedir. CNC ile yapılan New Orleans'daki Moma binası (Tablo 1-b) tüm yapının dijital olarak üretildiği ilk prototip yapı olarak gösterilmektedir. Diğer bir örnek ise Metropol Parasol (Jürgen Mayer H. Architects) projesidir (Tablo 1-a).

\section{A.1.2. Hizlı Prototipleme}

Hızlı prototipleme, kısaca bilgisayar kontrollü hareketlerle malzemenin katmanlar halinde işlenerek nesnelerin oluşturulması olarak tanımlanmaktadır. İşlemin başlatılma şekli genellikle CNC işlemleriyle benzerlik taşımaktadır [12]. Bilim dünyasında daha çok 3b baskı olarak kullanılan hızlı prototipleme; ekleyerek büyütme / ekleyerek üretme / katmanlı üretim olarak bilinmektedir (Tablo 1-c ve 2-d). Hizlı prototipleme zaman, maliyet ve uygulama açısından avantaj sağlamakta ve tasarımların farklı malzemeler ile üretilmesine imkân vermektedir.

\section{A.1.3. Robotlar}

Diğer bir dijital üretim aracı ise robotların kullanıldığı robotik uygulamalardır. CNC makineleri gibi, çalışmalarını yönlendirmek için bilgisayarlı veri ile beslenen robotlar ve robot kollar, sayısal verilere göre malzemeleri işlemekte, döndürmekte, delmekte, yatay ve dikey yönde yerleştirmektedir [22]. İlk inşaat robotları modüler evlerin prefabrikasyonunda kaliteyi artırmak için 70'li yılların başında Japonya'da tasarlanmıştır. Otomobil üretim süreçleri, gemi inşaatı ve kimya endüstrisinden alınan fikirler inşaat sektörüne uyarlanmıştır. Robotlar püskürtme, beton yumuşatma, malzeme dağıtma, tavana ekipman montaj1, kalıp montaj1, cephe montaj1, boyama, temizleme ve benzeri özel görevleri yerine getirmek üzere şantiye alanına girerek hesaplamalı montajda da kullanılmıştır [23]. Robotlar, endüstriyel robotlar ve uçan robotlar olarak ikiye ayrılmaktadır. Robot kol olarak anılan endüstriyel robotla inşa edilen Pike Loop yapısı (New York), geleneksel yapı malzemesi olan tuğladan yapılmış ve 22 metre uzunluğundadır. Tasarımın karmaşık geometrisi 7.000 'den fazla tuğlanın örülmesi ile üretilmiştir [21]. (Şekil 2-e). 
Uçuş montajlı mimarlık projesi 2011 yılında uçan robotlar tarafından inşa edilen ilk yapılardan biridir (Şekil 2-1). 600 m yüksekliğindeki dikey yerleşimin 1/100'lük modeli olarak düşünülen proje, dört uçan makine tarafından inşa edilmiştir. $6 \mathrm{~m}$ uzunluğundaki model, 1500 köpük tuğladan 18 saat içinde inşa edilmiştir. Son araştırmalardan biri olan "Hava İnşaatı: Uçan Makinelerle Çekme Yapılarının Robotik Üretimi" başlıklı çalışmada uçan makinelerle kablo sistemleri örülerek bir köprü oluşturulmuş daha sonra da uzay kafes sistemlerin montajı yapılmıştır (Şekil 2-i) [24, 28].

\section{A. 2. Sayısal Üretim Biçimine Göre Sınıflandırma}

Yukarıda anlatılan sayısal üretim araçları ile bilgisayar ortamında oluşturulan sayısal veriyi, fiziksel olarak üretebilmek için yapı bileşenleri ve yapı elemanlarını detaylandırabilmek için çeşitli sayısal üretim biçimlerine ihtiyaç duyulmaktadır [20]. Bu üretim biçimleri tasarlanan ürünün nasıl üretileceğini belirlemek için kullanılmaktadır. Üretim biçimine karar verirken tasarımın iki ya da üç boyutlu olması, tasarımın büyüklüğü ve sayısı, üretilecek malzemenin karakteri gibi özelliklerin bilinmesi gerekmektedir. Dunn [21] ve Kolarevic [20] bu üretim yöntemlerini dörde ayırmıştır;

\section{A.2.1. Kesmeye Dayalı Üretim}

Levhalar üzerine iki boyutlu CNC makinalarıyla yapılan ve yüzey üretimi sağlayan teknolojilerdir. Stuttgart'taki Gatehouse (2007), kesmeye dayalı üretim sistemleri kullanılarak yapılmıştır. Yapı için bir dizi atölye çalışması geliştirilmiştir. Yüzey geometrisini ve açıklıkların çatı düzlemi boyunca ilişkisini incelemek için lazer kesim ile ölçekli modeller aracılığıyla çeşitli çatı desenleri araştırılmışıı ve prototipler üretilmiştir [21] (Tablo 2-a).

\section{A.2.2. Çıkarmaya Dayalı Üretim}

Malzemenin, elektrokimyasal veya mekanik süreçlerle frezeleme işlemiyle katı bir malzemenin belirli bir kısmının çıkarılması işlemidir. Gehry'nin New York'taki Condé Nast Kafeterya (2000) projesinde, kompleks eğrisel yüzeylere sahip lamine cam panellerin üretimi için CNC kullanılmıştır [20] (Tablo 2b).

\section{A.2.3. Eklemeye Dayalı Üretim (Katmanlı Üretim)}

Eklemeli üretim (additive fabrication), katmanlı üretim (layered manufacturing), katıların serbest formlu üretimi (solid free form fabrication), hızlı prototiplendirme (rapid prototyping), masaüstü prototip (desktop manufacturing) gibi isimlerde kullanımları da görülmektedir [20]. Katmanlı üretim sürecinde malzemenin art arda eklenmesiyle ürün oluşturulmaktadır. Böylece, malzeme kaldırma, işleme, taşıma ve montajları gibi karmaşık işlemler çok sayıda aynı basit işleme indirgenmektedir [26]. 2016 yılında üretilen Daedalus Pavilyonu bu üretim yöntemi ile yapılmıştır (Tablo 2-c). Eklemeli üretim aşağıdaki avantajlarından dolayı birçok sektör de kullanılmaktadır [27, 28].

- Gerekli malzemeler kullanılarak bir kalıba ihtiyaç duymadan ürünler üretilmektedir.

- Maliyet ve zamandan tasarruf sağlanmaktadır.

- Üretim aletlerinin çeşitliliği azalmakta veya tamamen ortadan kalkmaktadır.

- Karmaşık formlarda müşteriye özel, tek seferlik ürünler tasarlanıp üretilmektedir.

- Atık maliyetleri azalmaktadır.

- Depolama ihtiyacı ortadan kalkmaktadır. 
Tablo 1. Sayısal üretim araçları ile yapılan projeler.

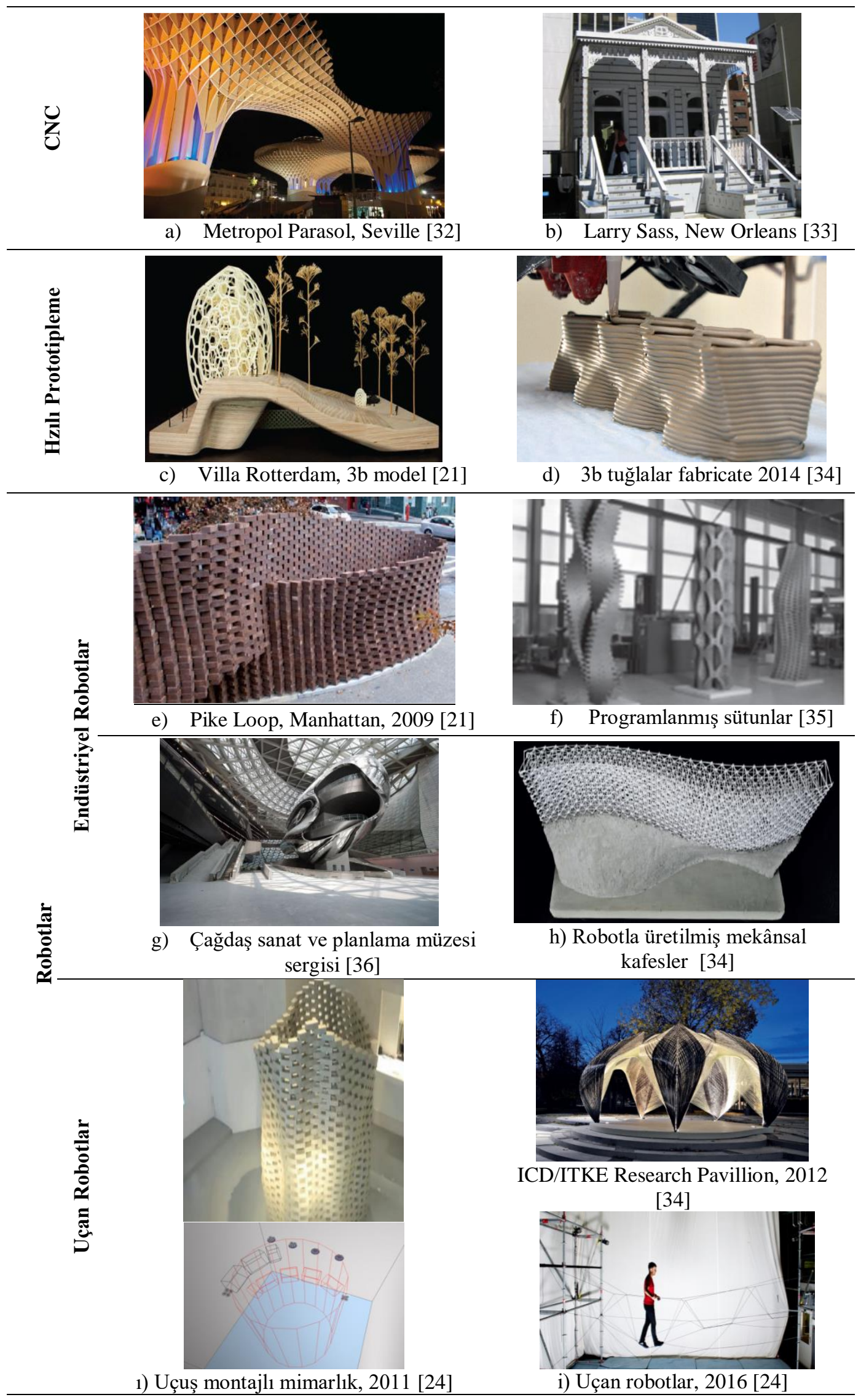


Tablo 2. Saylsal üretim biçimlerine örnek projeler.
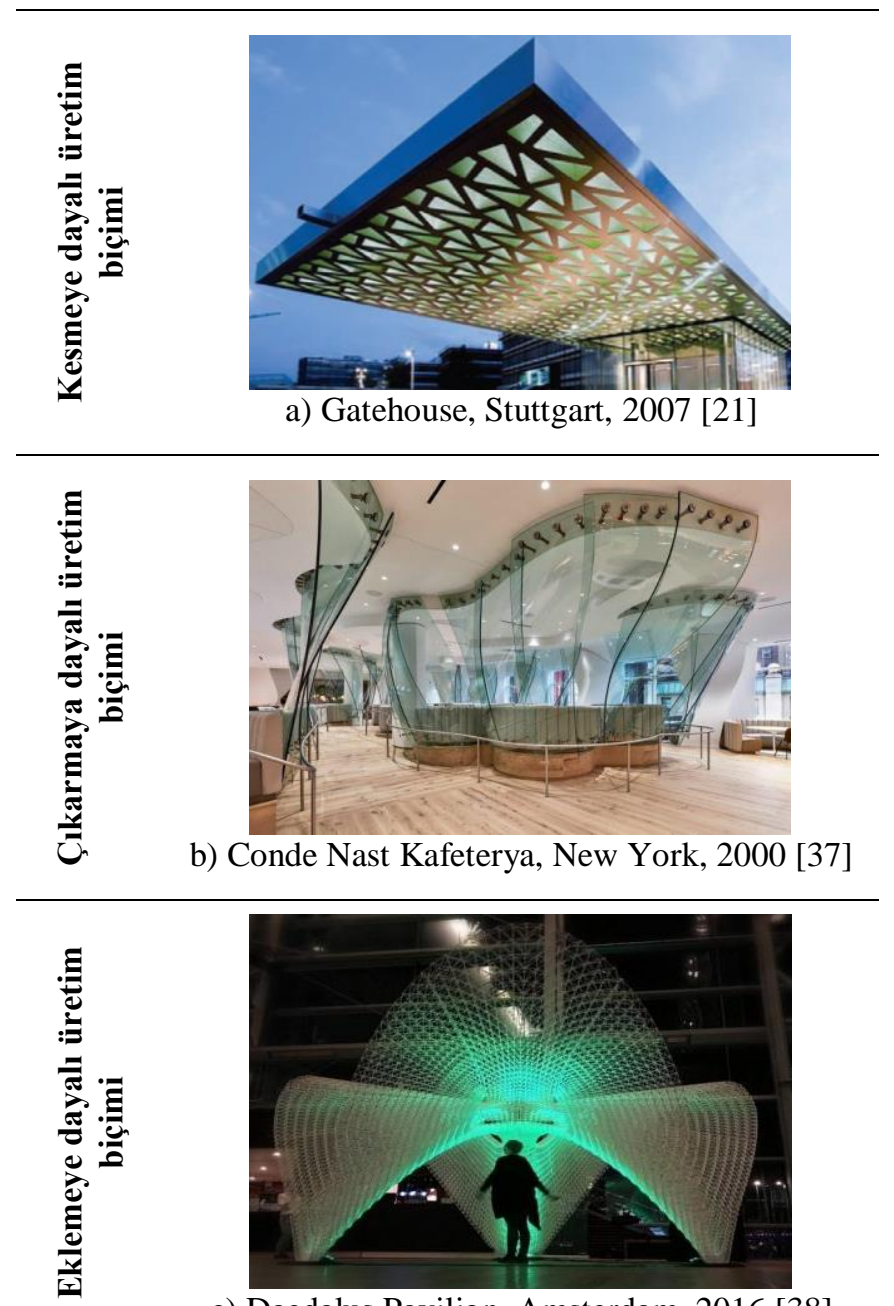

c) Daedalus Pavilion, Amsterdam, 2016 [38]

\section{A. 3. Sayısal Üretim Metotları}

Sayısal üretim biçimlerinin dışında tasarlanan ürünün; seçilen malzeme ile nasıl yapılacağını, nasıl biçim verileceğini yani nasıl uygulanacağını belirleyebilmek için çeşitli sayısal üretim metotları bulunmaktadır. Iwamoto [22] bu metotları aşağıdaki gibi 5'e ayırmıştır.

\section{A.3.1. Kesit Alma (Sectioning)}

Kesit alma yüzeyin kendisini inşa etmek yerine, bileşenlerin yüzey geometrisine göre profil oluşturma yöntemi olarak tanımlanmaktadır. Modelleme yazılımındaki kesit alma veya sınırlandırma komutlarının, belirli aralıklarla nesneler boyunca paralel kesitleri anında alabilmesi, seri hale getirilmiş paralel bölümler oluşturma işlemini etkili bir şekilde kolaylaştırmaktadır. Ronchamp şapeli, Yaşanabilir karton odaları ve C Space pavyonu örnek olarak gösterilmektedir [22] (Tablo 3-a).

\section{A.3.2. Mozaikleme (Tessellation)}

Bir düzlem veya yüzey oluşturmak için boşluklar olmadan birbirine uyan parçalardan oluşturulan bir derleme olarak tanımlanmaktadır. Sayısal tasarım terminolojisinde ise tek veya çift eğrili yüzeyleri 
poligonal ağlarla oluşturma olarak da tanımlanmaktadır. Fuller'in jeodezik kubbeleri, bu yaklaşımın ilk örnekleridir. Ayrıca Huyghe + Puppet Theater MOS yapısı ve BMW Welt projesinin çatısı örnek olarak gösterilmektedir [22] (Tablo 3-b).

Tablo 3. Kesit alma ve mozaikleme metotlarl kullanılan projeler.

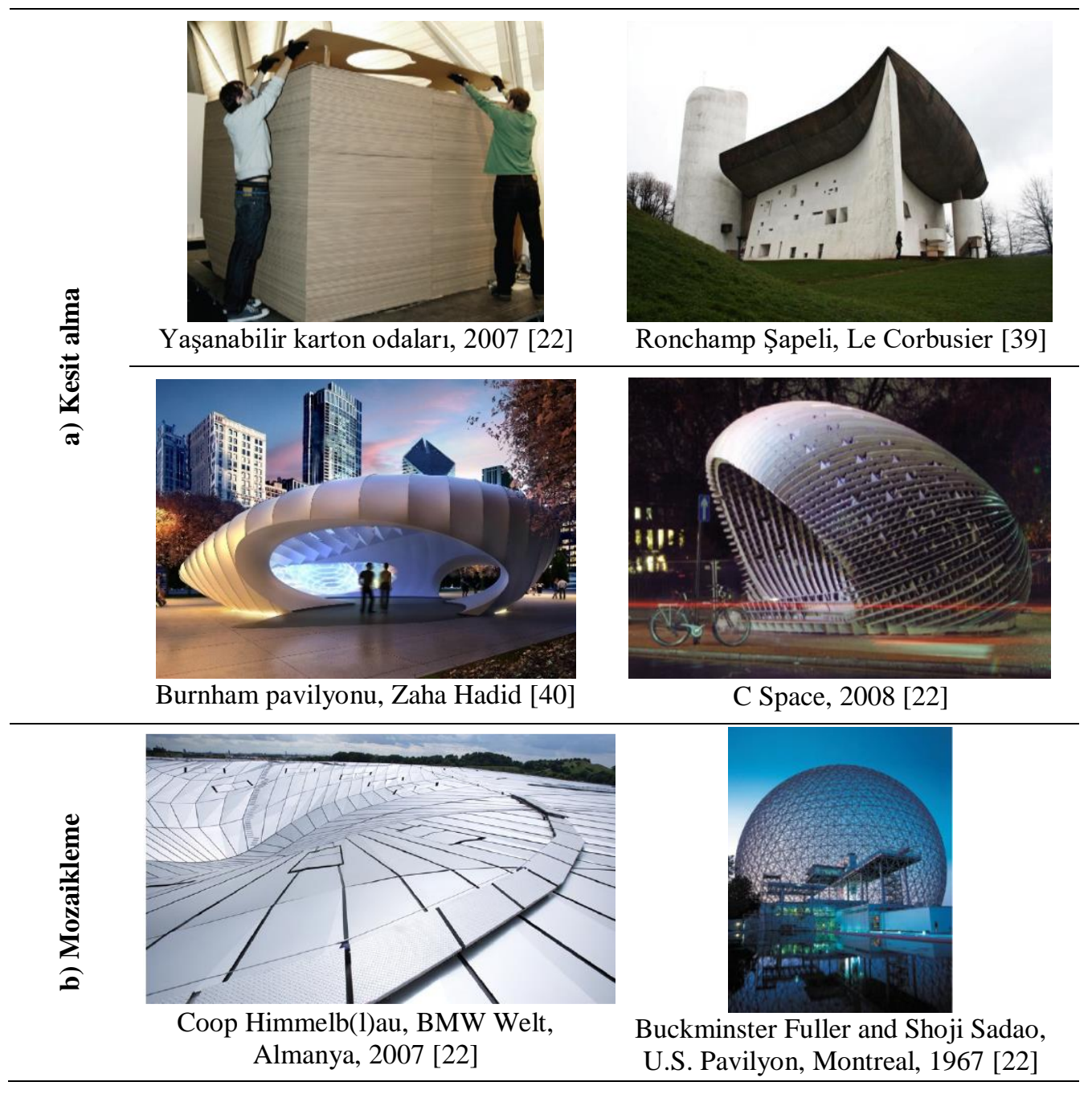

\section{A.3.3. Katlama (Folding)}

Katlama tekniği ile iki boyutlu düz bir yüzey üç boyutlu bir nesneye dönüştürülmektedir. Bu sayede hem form oluşturulmakta hem de ortaya çıkan geometri ile strüktürel dayanım sağlanmaktadır. 20 yıldan beri bu tekniği kullanan mimarlar, dereceli olarak artan eğimli yüzeyler, mekânlar ve formlar oluşturmuşlardır [22]. Bu teknikte lazer kesiciler malzemenin daha kolay bir şekilde katlanmasını sağlamak için tabaka kesmek yerine tabaka malzemesini yüzeyde tararken, diğer kesiciler katlanmaya yardımcı olmak için bir dizi delik ya da delikler oluşturmaktadır. Bu yüzden lazer kesiciler daha avantajlı olmaktadır. Yüzeyin kıvrımlar, kırışıklıklar ve diğer modülasyonlar vasıtasıyla kontrol edilmesi için, kullanılacak malzeme tabakasının doğada esnek olması gerektiğinden kalın kağıt, metal levha ve plastikler yaygın olarak kullanılmaktadır [21].

Katlama metotu ile tasarlanan yapıların en büyük örnekleri çatı yapılarıdır. Daha geniş açıklık ve daha uygun maliyetli yapı elde etme ihtiyacı bu tip bir yapının ortaya çıkmasına neden olmuştur. Katlama tekniği ile inşa edilen en önemli binalardan biri ABD'nin Colorado Springs'teki Hava Kuvvetleri Akademisi'ndeki Şapel'dir (Tablo 4-d) [41]. Tablo 4'de yer alan diğer projeler de katlama metoduna örnek olarak gösterilmektedir [21, 22]. 
Tablo 4. Katlama metotu kullanılan örnek projeler.

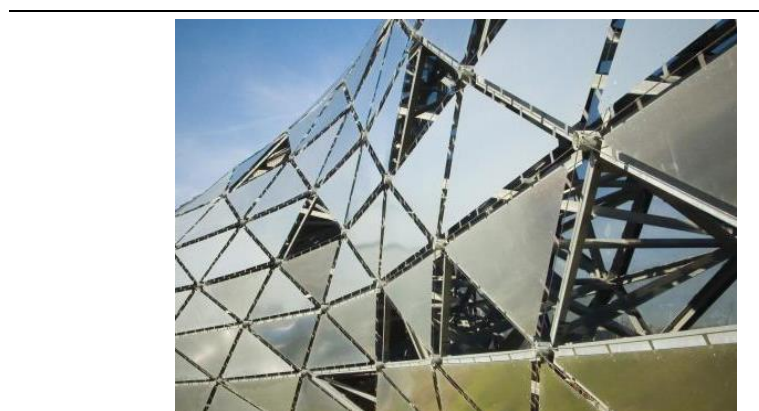

a) Akustik bariyer, Utrecht, ONL, 2006 [41]

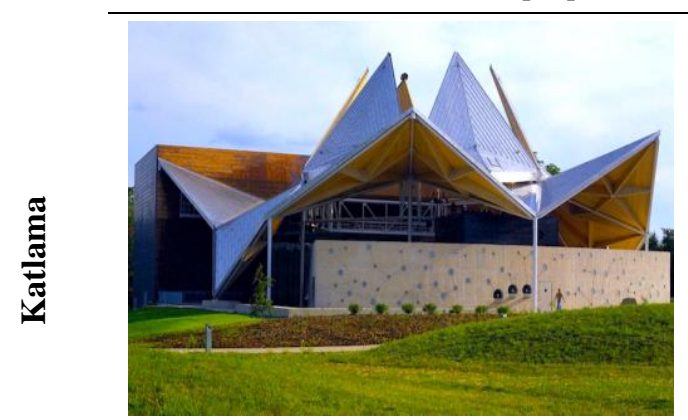

c) Starlight Theatre, Rockford [21]

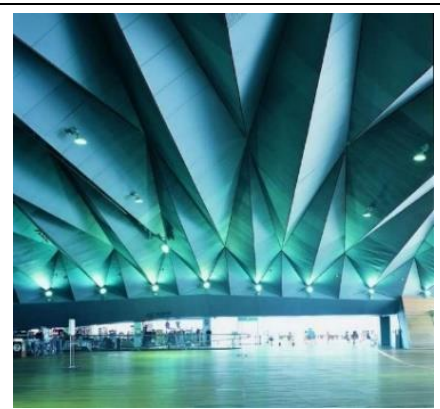

e) Yokohama Yolcu Terminali, 2002 [43]

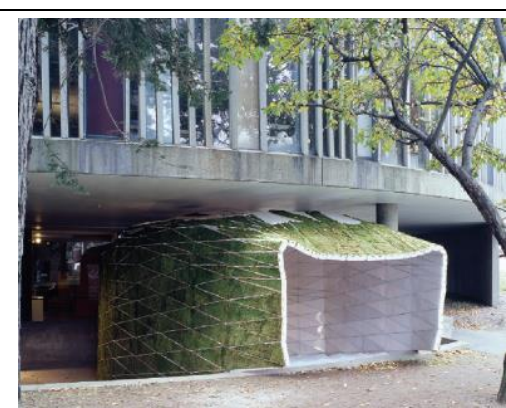

b) Huyghe + Le Corbusier Kukla Tiyatrosu MOS, 2004 [22]

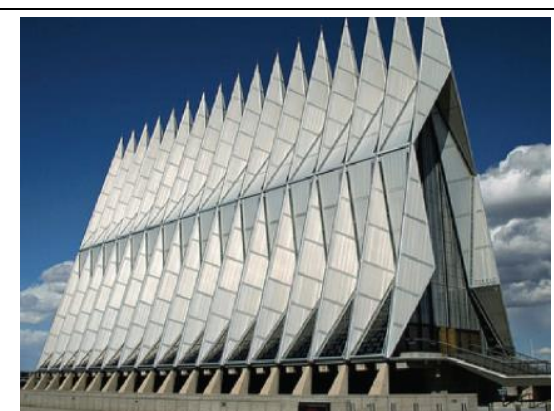

d) Hava kuvvetleri akademisi, 1962 [42]

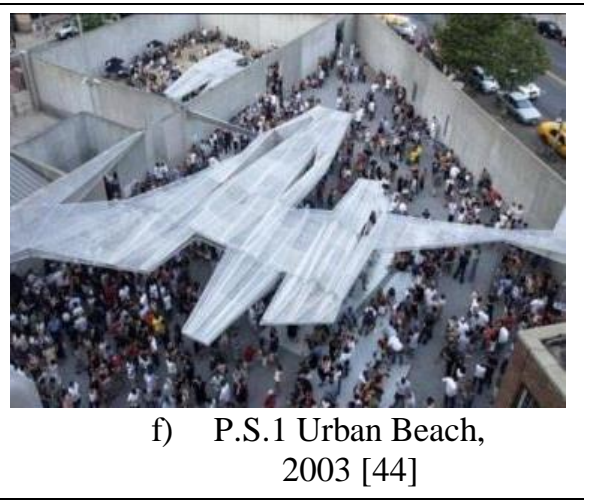

\section{A.3.4. Kontürleme (Contouring)}

Bu teknikte tabaka halinde bulunan kontrplaklar, taş tabakalar, suntalar, MDF'ler, alçıpanlar ve dökme kompozitler gibi iki boyutlu yüzeylerin oyularak yeniden şekillendirilmesiyle üretim yapılmaktadır. Çıkartma yöntemine dayalı bir üretimdir [22]. Bu metotta ahşap, köpük ve metaller kullanılmaktadır [21].

Heykeltıraş Erwin Hauer'in eserinden esinlenilerek tasarlanan kemik duvar ve Berkeley sanat müzesi ve Pasifik film arşivi için Faulders Studio tarafından tasarlanan ve tamamlanan BAMscape bu tekniğe örnektir [21, 22] (Tablo 5-a).

\section{A.3.5. Form Verme (Forming)}

Form verme metodunda, üretilmesi istenen bir biçime sahip kalıptan bileșenlerin işlenmesi ile üretim yapılmaktadır. Örneğin yeniden şekillendirilmiş metal malzeme, basınç ile elastik sınırın ötesine geçirilerek 1sıttlıp yumuşatılarak şekil verilmektedir. Bu teknik en çok tüketici ürünlerinin seri üretiminde, cephe panelleri, detay bileşenleri ve diğer donanımlar gibi mimari elemanların yapımında kullanılmaktadır [20, 21]. 
Etrafımıza baktığımızda gördügümüz ambalajlar, plastik oyuncaklar, cep telefonları, araba gövdeleri gibi birçok nesne form verme metotu ile üretilmektedir. Küçük bir malzemeden çok sayıda ürün oluşturulması nedeniyle, bu teknik kitlesel üretilmiş ürünlerde yaygın olarak kullanılmaktadır [22]. Form verme tekniğine Lounge peyzaj projesi oturma birimi örnek olarak gösterilmektedir (Tablo 5-b).

Tablo 5. Kontürleme ve form verme tekniği ile yapllan projeler.

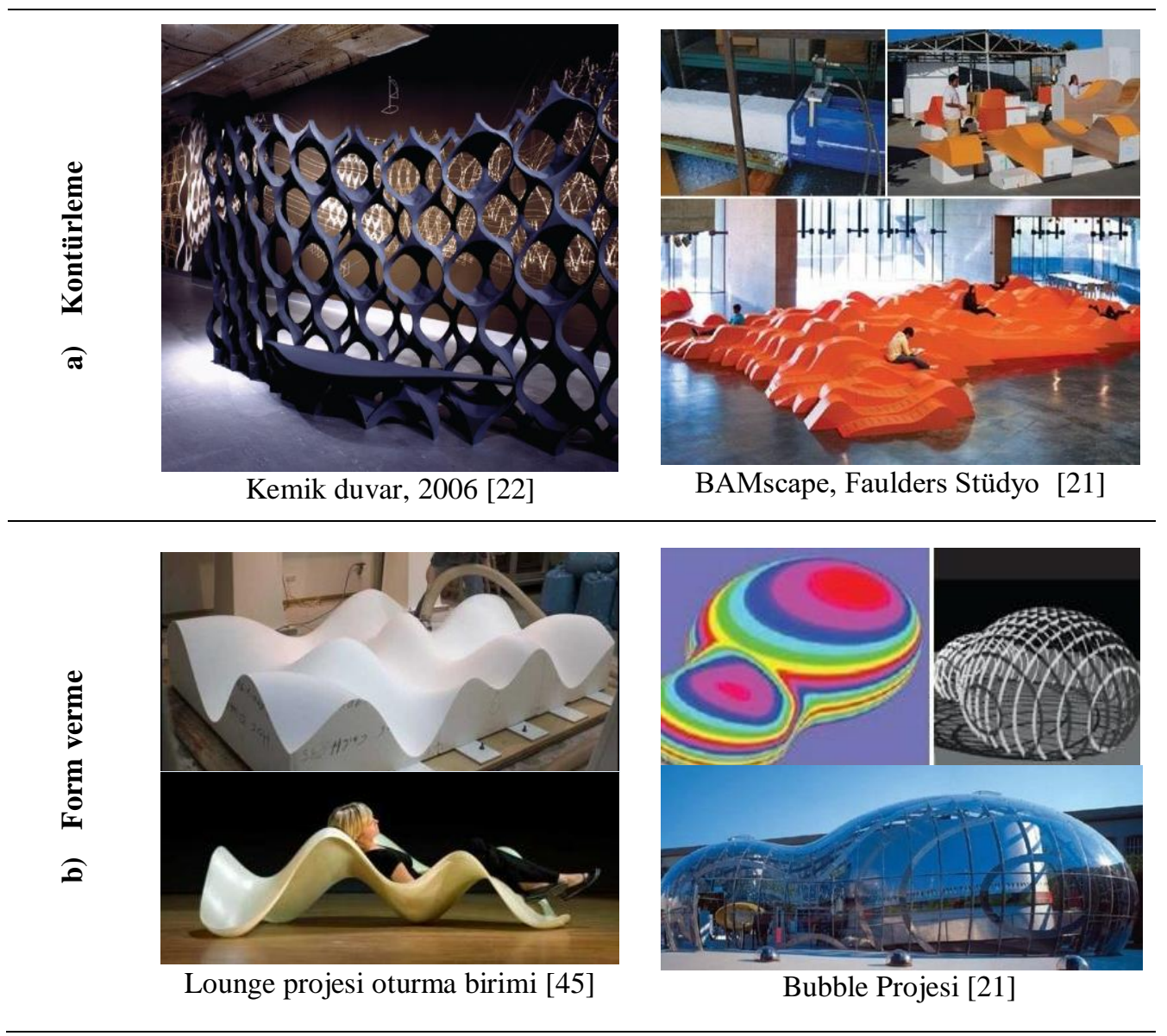

Frankurttaki BMW Ticaret Fuarı'ndaki Bubble projesi tasarımdan konstrüksiyona kadar tamamen dijital yollarla yapılmış ilk yapılar arasında gösterilmektedir (Tablo 5-b). Parametrik tasarım modeli ile tasarlanan yapının çerçevesi, tabaka alüminyumdan kesilen 3500 ayrı bileşenin üretilmesi ile oluşturulmuştur. 305 benzersiz akrilik-cam panelden oluşan kaplama elemanları, ayrı ayrı CNC-freze köpük blokları üzerine 1sı ile oluşturulmuştur. Soğuduktan sonra, hazırlık aşamasında her bir panel altyapıya bağlantı için kenarlarda kırpılmıştır [21].

\section{DEĞERLENDİRME VE SONUC}

Önceki bölümlerde anlatıldığı üzere sayısal üretim araçları, biçimleri ve metotları birbirlerini destekler nitelikte kavramlardır ve aralarındaki ilişkilerin bilinmesi önemli olmaktadır. Bu bakımdan mimaride kullanılan bilgisayar destekli fabrikasyon teknolojileri ve bu teknolojiler arasındaki ilişkiler Şekil 2'deki gibi sınıflandırılmıştır. Tasarım sürecinde bu kavramların iyi bilinmesi ile üretimin hangi üretim aracı, üretim biçimine ve metoduna göre yapılacağının belirlenmesi, süreçler açısından önem kazandırırken yapılacak hataların da minimumda olmasını sağlayacaktır. Bu kavramlar arasındaki ilişiklerden net olarak görülmektedir ki mimarlar tarafından ilk yapılması gereken, yapılan tasarıma ve kullanılacak malzemenin özelliklerine göre sayısal üretim biçimini, sayısal üretim metodunu ve aracını belirlemek olmalıdır. 


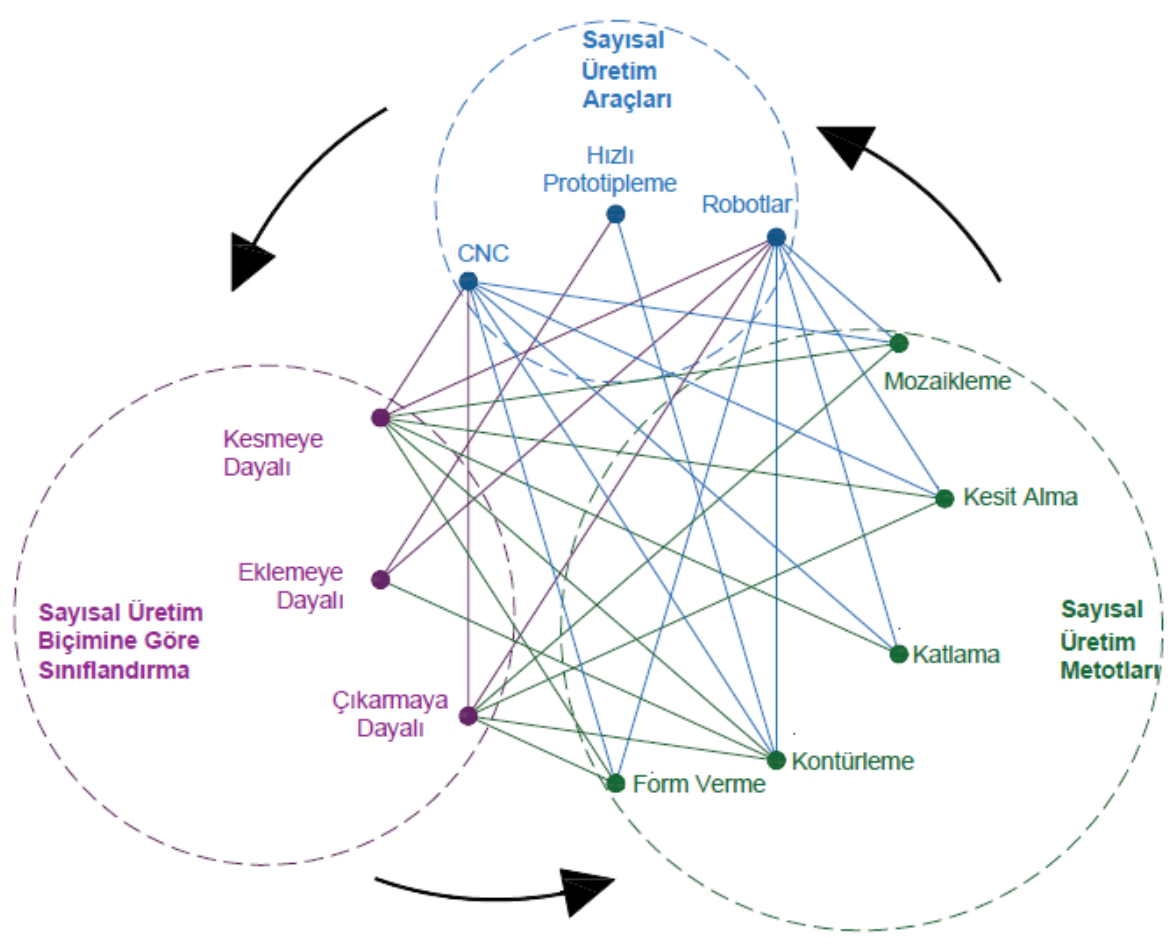

Şekil 2. Sayısal üretim araçları, sınıflandırmaları ve metotları (Yazarlar tarafindan oluşturulmuştur).

Yukarıda anlatılan yöntem, teknik ve metotlar ışığında özellikle de 2000'li yıllardan günümüze olan bu süreçte mimaride bilgisayar destekli tasarım ve üretim araştırmalarının ve projelerinin hız kazandığı söylenebilmektedir. Günümüzde bazı endüstrilerde projeler yalnızca dijital olarak tasarlanmakla kalmamakta, dosyadan-fabrikaya prensibiyle üretilmektedir. Ülkemiz de yapı sektöründe örnekleri olmasa da yurt dışında bununla ilgili yapılan ve devam etmekte olan çalışmalar bulunmaktadır. Dünya'da son 10 senedir gerçekleştirilen araştırmalar ve uygulamalar ile katmanlı üretim sistemleri ile 2 saatte üretilen mobil konutlar ve bir haftada üretilen konutlar yapılmaktadır. Hatta gelinen en son aşamada kendi kendini örgütleyen sistemler üzerine yapılan çalışmalar bulunmaktadır. Bu gelişmeler göz önüne alınarak gelecekte yapılacak yapıların tasarımı, üretimi ve uygulamasının yani tüm inşaat sürecinin insanlar olmadan bilgisayarlar ve robotlar ile üretileceği söylenebilmektedir. Ülkemizin bu gelişmelerin gerisinde kalmasının önüne geçebilmek adına bu konular ile ilgili bilincin ve bilginin arttırılması da kaçınılmaz olmaktadır. Bu bağlamda ele alınan mimaride bilgisayar destekli üretim araç, yöntem ve biçimi üzerine yapılan sınıflandırmanın mimarlara yol gösterici nitelikte olmas1 öngörülmektedir.

Ayrıca, sayısal üretim teknolojilerinin mimariye sağlayacağı avantaj ve katkılarda göz ardı edilmemelidir. Sayısal üretim ürün tasarlanması, üretilmesi süreçlerinde yaşanan problemlere çözüm sağlamaktadır. Mimaride ise bilgisayarda çizilen tasarımların benzetimlerinin yapılması ile üretim sürecindeki sorunlar üretim öncesi değerlendirilerek engellenebilmektedir. Hatta yukarıda anlatılan yöntem ve teknikler ile prototipler üretilmekte değişiklikler bunun üzerinden karar verilerek de yapılabilmektedir. Geleneksel yöntemlerle yapıldığında günler haftalarca süren üretimler sayısal üretim yöntemleri ile daha kısa sürede tamamlanmaktadır. Tasarımlar kişiye ve üretime yönelik olarak özelleşmekte ve özgün tasarımlar ortaya koyulmaktadır. Tasarımda ulaşılamayan karmaşık formlar dijital tasarım yöntemleri ile tasarlanarak dijital üretim yöntemleri ile üretilebilir duruma gelmesi ile de mimarların artık daha özgür tasarımlar yapabilmesi sağlanmaktadır. Bu teknolojilere yönelik farkındalığın arttırılması ile ülkemizde de zaman, maliyet ve işçilikten avantaj sağlayan yüksek bitmişlik düzeyinde yapıların üretilmesinin de mümkün olacağı öngörülmektedir. 


\section{KAYNAKLAR}

[1] M. Carpo, The Alphabet And The Algorithm (Writing Architecture). The MIT Press; 1 edition, February 4, 2011.

[2] C. A. Bennett, History Of Manual And Industrial Education, 1870 to 1917. The Manual arts press, Peoria, Illinois, 1937.

[3] E. C. Johnson, Marine Corps Aviation: The Early Years, 1912-1940. University of Michigan Library, 1977.

[4] N. Metropolıs, J. Howlett ve G. C. Rota, A History Of Computing In The Twentieth Century. Academic Press, 1980.

[5] B. Randell, The Origins of Digital Computers. Springer, Berlin, Heidelberg, 1982.

[6] W. Johanna, The History of the Industrial Robot. Linköping: Linköping University Electronic Press, 2008.

[7] M. E. Moran, "Evolution of Robotic Arms," J Robotic Surg, vol. 1, pp. 103-111, 2007.

[8] H. Lipson ve M. Kurman, Fabricated: The New World of 3D Printing. John Wiley \& Sons Inc., 2013.

[9] B. Streich, B. ve W. Weisgerber, Computergestützter Architekturmodellbau: CAAD Grundlagen Verfahren, Beispiele. Birkhäuser, 1996.

[10] A. Simondetti, "Rapid Prototyping in Early Stages of Architectural Design," Master of Science Thesis, MIT, 1997.

[11] J. Breen, R. Nottrot ve M. Stellingwerff, "Tangible Virtuality - Perceptions of Computer-Aided and Physical Modelling," Automation in Construction, vol. 12, no. 6, pp. 649-653, 2003.

[12] J. Seely, "Digital Fabrication In The Architectural Design Process," Master of Science in Architecture Studies at the Massachusetts Institute of Technology, 2004.

[13] P. Blikstein, "Digital Fabrication and 'Making' in Education: The Democratization of Invention," In FabLabs: Of Machines, Makers and Inventors, J. Walter-Herrmann \& C. Büching (Eds.), Bielefeld: Transcript Publisher, 2013.

[14] M. Botha ve L. Sass, "Instant House: Design and Digital Fabrication of Housing for Developing Environments," The Association for Computer Aided Architectural Design Research CAADRIA: Rhythm and Harmony in Digital Space, Kumamoto, pp. 209-216, 2016.

[15] T. Bonwetsch, F. Gramazio ve M. Kohler, "Digitales Handwerk," GAM Architecture Magazine 06, Springer, Vienna, , vol. 6, pp. 172-179, 2010.

[16] F. Gramazio ve M. Kohler, Digital Materiality in Architecture. Lars Müller Publishers, Baden, 2008.

[17] A. J, Rocha, Architecture Theory 1960-1980: Emergence of a Computational Perspective. Massachusetts Institute of Technology, ABD, 2004. 
[18] F. Scheurer, "Architectural CAD/CAM: Pushing the Boundaries of CNC Fabrication in Building," in Manufacturing material effects: Rethinking design and making in architecture, B. Kolarevic, K. Klinger K. (Eds.), New York: Routledge, pp. 211-222, 2008.

[19] F. Gehry. (2018, April 10). Fish sculpture in Barcelona [Online]. Available: https://www.archdaily.com/773232/9-entreprenurial-architects-who-developed-innovative-productsand-services/55ee0ddbe58ece95a8000019-9-entreprenurial-architects-who-developed-innovativeproducts-and-services-image

[20] (2018, April 10). Guggenheim Bilboa (1997) [Online]. Available: https://www.archdaily.com/778151/paul-goldberger-frank-gehry-really-doesnt-want-to-beremembered-as-somebody-who-just-did-a-few-iconic-buildings/565f0003e58ece20b4000229-paulgoldberger-frank-gehry-really-doesnt-want-to-be-remembered-as-somebody-who-just-did-a-fewiconic-buildings-photo

[21] D. Sokol ve N. Mafi. (2019, February 15). 31 Spectacular Buildings Designed by Frank Gehry [Online]. Available: https://www.architecturaldigest.com/gallery/best-of-frank-gehry-slideshow

[22] A. Picon, Digital Culture in Architecture: An Introduction for the Design Professions. Birkhäuser Basel, 2010.

[23] B. Kolarevic, Architecture in the Digital Age: Design and Manufacturing. London: Spon Press, 2003.

[24] N. Dunn, Digital Fabrication in Architecture. Laurence King Publishing, 2012.

[25] L. Iwamoto, Digital Fabrications: Architectural and Material Techniques. New York: Princeton Architectural Press, 2008.

[26] D. Wolf \& Partner ZT GmbH. (2015, February 23). We Start The Future of Construction [Online]. Available: https://m.youtube.com/watch?v=R64IEixoYJ0

[27] A. Mirjan, "Aerial Construction: Robotic Fabrication of Tensile Structures with Flying Machines," Doctoral Thesis, ETH Zurich, 2016.

[28] F. Augugliaro, S. Lupashin, M. Hamer, C. Male, M. Hehn, M. W. Mueller, J. S. Willmann, F. Gramazio, M. Kohler ve R. D'Andrea, "The Flight Assembled Architecture Installation: Cooperative construction with flying machines," IEEE Control Systems Magazine, vol. 34, no. 4, pp. 46-64, 2014.

[29] J. Pegna, "Exploratory İnvestigation of Solid Freeform Construction," Automation in Construction, vol. 5, no. 5, pp. 427-437, 1997.

[30] D. Bryden, CAD and Rapid Prototyping for Product Design. Laurence King Publishing, 2014.

[31] N. Hopkinson ve P. Dickens, "Analysis of Rapid Manufacturing - Using Layer Manufacturing Processes for Production," Proceedings of the Institute of Mechanical Engineers, Part C: Journal of Mechanical Engineering Science, vol. 217, no. 1, pp. 31-39, 2003.

[32] M. S. Uihlein, "Architecture, Structure, and Loads: A Moment of Change?, ARCC JOURNAL vol. 9, no.1, pp. 53-61.

[33] D. Smithwick, D. Michaud, L. Rushfelt, L. Davis. (2019, May 12). Digitally Fabricated House for New Orleans (2017-2018) [Online]. Available: https://ddf.mit.edu/milestones/03 
[34] F. Gramazio, M. Kohler, S. Langenberg, Fabricate 2014 Negotiating Design \& Making. UCL Press, 2014.

[35] R. Glynn ve B. Sheil, Fabricate: Making digital architecture. UCL Press, 2011.

[36] (2018, May 15). Çağdaş Sanat ve Planlama Sergisi Binası Coop Himmelb(l)au [Online]. Erişim: http://mimdap.org/2016/10/cadhdath-sanat-ve-planlama-sergisi-binasy-coop-himmelblau/

[37] E. Fazzare. (2019, May 15) Studios Architecture Revamps the Frank Gehry-Designed Former Condé Nast Cafeteria [Online]. Available: https://www.architecturaldigest.com/story/frank-gehrystudios-architecture-conde-nast-cafeteria

[38] (2020, March 8) Daedalus Pavilion [Online]. Available: https://parametrichouse.com/daedaluspavilion/

[39] S. Medina. (2019, Jenuary 27). Le Corbusier's Ronchamp, Vandalized [Online]. Available: https://www.archdaily.com/469008/le-corbusier-s-ronchamp-

vandalized/52dd58b3e8e44e45120001da-le-corbusier-s-ronchamp-vandalized-photo

[40] (2018, April 21). Zaha Hadid Architects Burnham Pavilion [Online]. Available: https://www.zahahadid.com/architecture/burnham-pavillion/

[41] (2018, May 12). VAA.ONL - the innovation studio of VAA [Online]. Available: https://archello.com/brand/vaaonl-the-innovation-studio-of-vaa4

[42] N. Šekularac, J. Ivanović Šekularac ve J. Č. Tovarović, "Folded Structures In Modern Architecture," Facta Universitatis Series: Architecture and Civil Engineering, vol. 10, no. 1, pp. 1-16, 2012.

[43] F. Agis. (2018, April 21). Yokohama International Port Terminal [Online]. Available: https://wordlesstech.com/yokohama-international-port-terminal/

[44] C. Zevi. (2018, May 5). What Happens to PSI's Young Architect's Program Projects at the End of the Summer? [Online]. Available: https://news.artnet.com/art-world/ps1-young-architects-programsummer-324297

[45] A. Menges. (2018, March 15). Lounge Landscape [Online]. Available: http://www.achimmenges.net/?p=4467 